\title{
Recent progress toward reducing the uncertainty in tropical low cloud feedback and climate sensitivity: a review
}

\author{
Youichi Kamae ${ }^{1,2^{*}} \mathbb{D}$, Tomoo Ogura ${ }^{3}$, Hideo Shiogama ${ }^{3}$ and Masahiro Watanabe ${ }^{4}$
}

\begin{abstract}
Equilibrium climate sensitivity (ECS) to doubling of atmospheric $\mathrm{CO}_{2}$ concentration is a key index for understanding the Earth's climate history and prediction of future climate changes. Tropical low cloud feedback, the predominant factor for uncertainty in modeled ECS, diverges both in sign and magnitude among climate models. Despite its importance, the uncertainty in ECS and low cloud feedback remains a challenge. Recently, researches based on observations and climate models have demonstrated a possibility that the tropical low cloud feedback in a perturbed climate can be constrained by the observed relationship between cloud, sea surface temperature and atmospheric dynamic and thermodynamic structures. The observational constraint on the tropical low cloud feedback suggests a higher ECS range than raw range obtained from climate model simulations. In addition, newly devised modeling frameworks that address both spreads among different model structures and parameter settings have contributed to evaluate possible ranges of the uncertainty in ECS and low cloud feedback. Further observational and modeling approaches and their combinations may help to advance toward dispelling the clouds of uncertainty.
\end{abstract}

Keywords: Climate sensitivity, Cloud feedback, Multi-model ensemble, Perturbed physics ensemble

\section{Introduction}

Physical predictions of the Earth's climate variability and changes are ongoing challenges for the geoscience community. Uncertainty in equilibrium climate sensitivity (ECS), determined by global mean surface air temperature (SAT) increase at a state of climatic equilibrium according to doubling of atmospheric $\mathrm{CO}_{2}$, is an unresolved issue in the climate science (e.g., Knutti and Hegerl 2008). While climate scientists are devoted to the development of realistic and reliable climate models, the uncertainty range of the modeled ECS has not been reduced efficiently since the Charney report (Charney et al. 1979) published in 1979 (Maslin and Austin 2012). The state-of-the-art estimates of ECS and transient climate response (TCR; a response of global-mean SAT to a gradually increasing atmospheric $\mathrm{CO}_{2}$ concentration)

\footnotetext{
*Correspondence: kamae.yoichi.fw@u.tsukuba.ac.jp

${ }^{1}$ Faculty of Life and Environmental Sciences, University of Tsukuba, 1-1-1 Tennoudai, Tsukuba, Ibaraki 305-8506, Japan

Full list of author information is available at the end of the article
}

from historical observations also have substantial uncertainty (e.g., Flato et al. 2014) due to difficulty in accurate estimations of ocean heat uptake and forcing (e.g., Yoshimori et al. 2016). Inter-model spread in feedback between the cloud and the top of the atmosphere (TOA) radiation, particularly shortwave reflectance due to cloud in the tropics, has been suggested to be the major factor for the uncertainty in ECS (e.g., Cess et al. 1990; Dufresne and Bony 2008; Boucher et al. 2014; Caldwell et al. 2016). In contrast to a less uncertain cloud feedback over land (Kamae et al. 2016a), large uncertainty in cloud feedback over the ocean contributes predominantly to the total spread of modeled ECS (e.g., Bony and Dufresne 2005; Webb et al. 2006; Vial et al. 2013).

Recent enormous challenges for quantifying and reducing the uncertainty in cloud feedback have been led by an international research framework called Cloud Feedback Model Intercomparison Project (CFMIP; e.g., Bony et al. 2015; Webb et al. 2016). In the CFMIP framework together with related research projects, a variety of approaches have been conducted: multi-model ensemble 
using climate models developed by different modeling centers independently (e.g., Andrews et al. 2012a; Zelinka et al. 2013; Vial et al. 2013), perturbed physics ensemble (PPE; detailed in a later section) focusing on the sensitivity of model physics (e.g., cumulus convection, cloud microphysics, and turbulence) on parameter settings (e.g., Collins et al. 2011; Klocke et al. 2011; Shiogama et al. 2012), climate models which have physics schemes swapped (Gettelman et al. 2012; Watanabe et al. 2012b) or turned off (Webb et al. 2015), simplified aqua planet simulations (e.g., Wang et al. 2012; Stevens and Bony 2013; Medeiros et al. 2014), single column models simulating one-dimensional atmospheric column (e.g., Zhang et al. 2013; Dal Gesso et al. 2015), high-resolution models resolving the cloud-convection system (Wyant et al. 2009; Sato et al. 2014; Bretherton 2015), or large eddy simulations (LES; e.g., Blossey et al. 2013; Bretherton et al. 2013; Bretherton and Blossey 2014). Satellite observations have been applied to assess the performance of climate model simulations and evaluate cloud feedback in a warming climate by using satellite simulators implemented in climate models (e.g., Klein and Jakob 1999; Webb et al. 2001; Bodas-Salcedo et al. 2011; Pincus et al. 2012).

One of the recent remarkable progresses is quantitative decomposition and physical understanding of the different roles of surface temperature-mediated changes and adjustment of the climate system to the imposed external forcing (Gregory and Webb 2008; Kamae and Watanabe 2013; Andrews and Ringer 2014; Ogura et al. 2014). Decomposition of the temperature-mediated cloud change (cloud feedback) and rapid cloud adjustment to increasing $\mathrm{CO}_{2}$ contribute to accurate evaluations of cloud feedback (Watanabe et al. 2012a; Webb et al. 2013; Vial et al. 2013; Zelinka et al. 2013). Comprehensive reviews on the rapid cloud adjustment can be found in Andrews et al. (2012b), Sherwood et al. (2015), and Kamae et al. (2015).

Cloud feedback contributing to the uncertainty in ECS has been evaluated by being separated into different cloud properties (fractional coverage, cloud top height, and optical depth; Zelinka et al. 2013; Boucher et al. 2014). In addition to the tropical low cloud feedback, feedbacks due to tropical high clouds (Hartmann and Larson 2002; Zelinka and Hartmann 2010; Mauritsen and Stevens 2015) and middle latitude mixed-phase clouds (Zelinka et al. 2012b; Ceppi and Hartmann 2015; Ceppi et al. 2016; Tan et al. 2016) have also attracted much attention because of its importance for the total uncertainty in cloud feedback and resultant ECS uncertainty. In this paper, we review the recent progress and remaining issues on understanding of the tropical low cloud feedback. Recently, observational constraints of the low cloud feedback and evaluation of possible uncertainty ranges including sensitivity of physics schemes have much advanced. We mainly introduce two papers (Sherwood et al. 2014; Qu et al. 2015b) as examples of the recent works on the observational constraint of the low cloud feedback. In addition, we pick up and introduce a series of modeling approaches evaluating parametric and structural uncertainty in cloud feedback and ECS. Stephens (2005); Boucher et al. (2014); Fasullo et al. (2015); Klein and Hall (2015); and Bretherton (2015) also provided comprehensive reviews on the uncertainty in cloud feedback and ECS.

\section{Observed and modeled variations in tropical low cloud}

For physical predictions of change in shortwave reflectance due to tropical low cloud cover (LCC) in a warming climate, regional and temporal correspondences between LCC and large-scale conditions were examined by observations and models (Table 1 ). In this paper, we mainly discuss LCC change over the subtropical ocean where stratocumulus and cumulus clouds dominate. Subtropical boundary layer (BL) cloud typically exists over the regions characterized by low sea surface temperature (SST), strong capping inversion, middle tropospheric subsidence, and cold air advection at the surface (Klein et al. 1995). Clement et al. (2009) found that the northeast Pacific LCC, lower tropospheric inversion, and vertical velocity at $500 \mathrm{hPa}$ are positively correlated over interannual and decadal time scales. The respective contribution of each large-scale property to the LCC change was examined by seasonal, interannual, and decadal correspondences between the two (e.g., Myers and Norris 2013, 2015). Here, we should note that a stronger regional anomaly compared with the tropical mean (e.g., stronger subsidence) does not necessarily correspond to an increase in LCC (detailed below; Myers and Norris 2013). Increasing SST, frequently used as a surrogate of climate change (Cess et al. 1990; Ringer et al. 2014), generally results in a reduced LCC through changes in surface latent heat flux and moisture contrast between the $\mathrm{BL}$ and free troposphere (FT). Increased surface latent heat flux enhances mixing of the dry FT air and moist BL, leading to a deeper BL and a less LCC (Chung and Teixeira 2012; Rieck et al. 2012). Moister BL under a higher SST condition (via increased surface moisture supply) results in an enhanced BL-FT moisture contrast. The enhanced contrast leads to a stronger drying effect of the mixing of the FT air at the capping inversion, resulting in a reduced LCC (Brient and Bony 2013) and a deeper BL (van der Dussen et al. 2015). In addition, uncertainty in regional SST warming pattern is tightly associated with cloud feedback through changing large-scale 
Table 1 Factors for low cloud feedback

\begin{tabular}{|c|c|c|c|}
\hline & $\begin{array}{l}\text { Change in a warming } \\
\text { environment }\end{array}$ & $\begin{array}{l}\text { Resultant changes in BL } \\
\text { and cloud }\end{array}$ & $\begin{array}{l}\text { Resultant low cloud } \\
\text { feedback }\end{array}$ \\
\hline SST (Hanson 1991; Clement et al. 2009) & Increasing & Deeper BL, less cloud & Positive \\
\hline $\begin{array}{l}\text { SST-related process: Surface evaporation (Chung and Teix- } \\
\text { eira 2012; Rieck et al. 2012) }\end{array}$ & Increasing & Deeper BL, less cloud & Positive \\
\hline $\begin{array}{l}\text { SST-related process: Moisture contrast at inversion (Brient } \\
\text { and Bony 2013; van der Dussen et al. 2015) }\end{array}$ & Increasing & Deeper BL, less cloud & Positive \\
\hline $\begin{array}{l}\text { Strength of inversion (Klein and Hartmann 1993; Wood and } \\
\text { Bretherton 2006) }\end{array}$ & Increasing & Shallower BL, more cloud & Negative \\
\hline $\begin{array}{l}\text { FT relative humidity (Klein et al. 1995; Lacagnina and Selten } \\
\text { 2013; Myers and Norris 2015) }\end{array}$ & Decreasing & $\begin{array}{l}\text { Decreasing high and middle } \\
\text { clouds, but uncertain in low cloud }\end{array}$ & Uncertain \\
\hline FT subsidence (Myers and Norris 2013) & Weakening & Higher cloud top, more cloud & Negative \\
\hline Surface wind speed (Klein et al. 1995; Qu et al. 2015b) & Uncertain & & Uncertain \\
\hline $\begin{array}{l}\text { Cold advection (Klein et al. 1995; Mansbach and Norris } \\
\text { 2007; Myers and Norris 2015) }\end{array}$ & Enhanced & More convective BL, more cloud & Negative \\
\hline
\end{tabular}

Left column indicates physical processes affecting low cloud cover (LCC) over the subtropical ocean. The second, third, and fourth columns from the left indicate the projected change in a warming climate, resultant change in low cloud and boundary layer (BL), and resultant low cloud feedback, respectively (Qu et al. 2015b; Myers and Norris 2016)

atmospheric circulations (Andrews et al. 2015; Long et al. 2016; Ying and Huang 2016).

The strength of inversion that caps the planetary $\mathrm{BL}$ controls the amount of BL cloud (Table 1). The stronger inversion suppresses the mixing of moist BL air with warmer and drier FT air, resulting in a shallower, moister, and cloudier BL (Klein and Hartmann 1993; Wood and Bretherton 2006). Strengthened subsidence in FT alone reduces the LCC, although subtropical low cloud exists over the regions where the subsidence dominates (Myers and Norris 2013). This paradoxical relationship can be explained by differences in relative contributions of the inversion strength and subsidence to LCC (stronger inversion causes an increase in the LCC and stronger subsidence reduces it a little). The relationship between FT relative humidity and LCC cannot be simply evaluated (Table 1). While high and middle cloud covers correspond well with the FT humidity (Albrecht et al. 1995), both decrease (Klein et al. 1995) and increase (Lacagnina and Selten 2013) in LCC associated with increased FT relative humidity were reported. Myers and Norris (2015) pointed out that increase in lower tropospheric $(700 \mathrm{hPa})$ humidity corresponds to decrease in cloud cover in $700-850 \mathrm{hPa}$ layer and increase just below and above that layer, resulting in the diverse conclusions. Variation in surface wind speed shows a high correlation with the LCC (a higher wind speed corresponds to a larger LCC; Klein et al. 1995). Enhanced cold air advection near the surface is concurrent with stronger convective mixing in the BL and increased LCC (Klein et al. 1995; Mansbach and Norris 2007; Myers and Norris 2015). These observations and modeling-based relationships between the LCC and the large-scale conditions can be applied to longer-term cloud changes including cloud feedback in a warming climate (see next section).

\section{Constraining the uncertainty in low cloud feedback}

There are attempts to reduce the large inter-model spread of ECS using observation-based performance metrics called emergent constraints (Sherwood et al. 2014; Klein and Hall 2015; Fasullo et al. 2015). Recent studies applied the observed relationship between the LCC variation and the large-scale atmospheric and SST conditions (Table 1) for reducing the uncertainty in the low cloud feedback in a changing climate (e.g., Dessler 2013; Zhai et al. 2015; Qu et al. 2015b; Myers and Norris 2016; Brient and Schneider 2016). Most of the observation-based approaches rely on an assumption that long-term change in the low cloud is largely controlled by changes in large-scale atmospheric condition and SST, so that the low cloud sensitivities are similar between the long-term change and seasonal, interannual, and decadal variabilities. Zhou et al. (2015) pointed out that long-term net cloud feedback tends to be smaller than interannual cloud feedback, although the two correspond well qualitatively among multi-models participated in the Coupled Model Intercomparison Project (CMIP). Difference in spatial patterns of SST perturbations between the two (long-term and interannual feedbacks) was suggested to be a factor for the difference in the cloud feedback, consistent with Andrews et al. (2015). Zhai et al. (2015) examined the seasonal relationship between SST and marine BL cloud in observations and CMIP models. They found that (1) modeled long-term correspondence between the two (SST and marine BL cloud) is similar to seasonal correspondence among the CMIP models and (2) models with 
realistic SST-cloud relationship compared with observations on seasonal timescale tend to have larger long-term positive cloud feedback, suggesting a higher ECS than the raw estimate from the CMIP models. Tsushima et al. (2013) evaluated representations of seasonal variations of cloud radiative effects of cloud regimes in climate models and found that models that capture the seasonal variation of stratocumulus cloud regimes tend to have higher ECS.

Qu et al. (2015b) developed a heuristic model relating future LCC change to changes in the atmospheric conditions and SST (Table 1). They found that three large-scale controls are dominant: strength of temperature inversion, strength of BL-FT humidity contrast, and surface latent heat flux (Fig. 1). This approach is an extension from $\mathrm{Qu}$ et al. (2014), which examined the SST effect as a surrogate for multiple processes including the latter two (latent heat release and humidity gradient; Fig. 1; Table 1). Contribution of the inversion strength (negative feedback) is relatively smaller than the total contribution of the SST (positive feedback; Table 1; Fig. 1), resulting in a small positive feedback (reduction of LCC) in a multimodel ensemble mean. By comparing with observed LCC sensitivity to the predictor variables, they concluded that observations suggest a systematic LCC reduction $(-7$ to $-3 \%$ during the twenty-first century) and a reduced reflection of solar radiation under a warming climate $(\mathrm{Qu}$ et al. 2015b). Myers and Norris (2016) also conducted a similar analysis and concluded that the SST effect and the inversion effect largely compensate each other, leading to a weak positive cloud feedback $\left(0.4 \pm 0.9 \mathrm{~W} \mathrm{~m}^{-2} \mathrm{~K}^{-1}\right)$ while uncertainty ranges due to observations and regression method are both substantial.

The analyses conducted in Qu et al. (2015b) and Myers and Norris (2016) exhibited that contributions of the three (inversion strength, humidity contrast, and latent heat flux) to LCC change are dominant compared with the other factors (Table 1). The CMIP models tend to show decreasing trends in the subtropical FT relative humidity in a warming climate (Sherwood et al. 2010; Qu et al. 2015b). However, the contribution of the FT relative humidity to the future LCC change is not robust among the models (Qu et al. 2015b; Myers and Norris 2016). Future change in sea surface wind speed is also highly uncertain among multi-models, resulting in a minor contribution compared with the others (Qu et al. 2015b).

Sherwood et al. (2014) suggested an emergent constraint, lower tropospheric mixing (LTM), for the uncertainty in low cloud feedback and ECS. The LTM, namely

\section{a Effect of Inversion Strength}

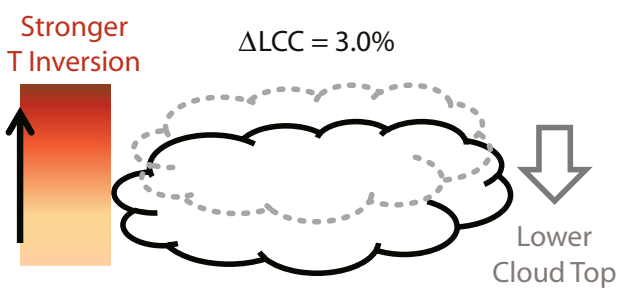

\section{b Effect of Humidity Contrast}

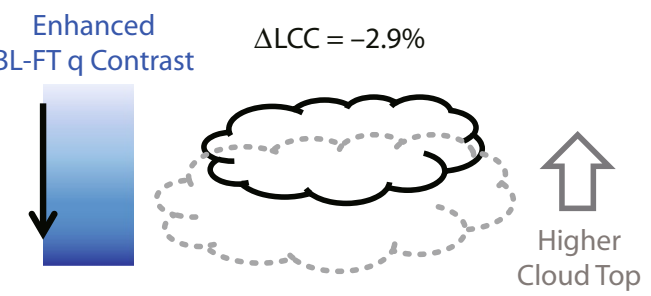

\section{c Effect of Latent Heat Flux}

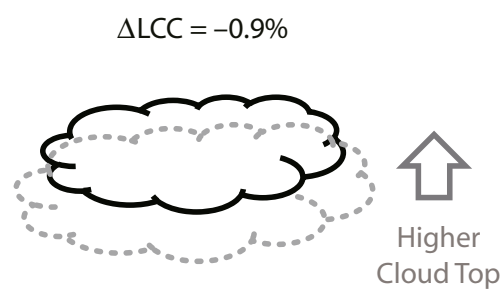

Increased Surface Latent Heat Flux

Fig. 1 Summary of key processes associated with low cloud feedback. Dashed gray and solid black balloons represent low clouds over the subtropical ocean in a base state and in a warmer condition, respectively. See Table 1 for references. a Effect of change in inversion strength. b Effect of sea surface temperature (SST)-induced moisture contrast between the boundary layer (BL) and free troposphere (FT). c Effect of SST-induced latent heat flux. Values shown in individual panels are multi-model mean of low cloud cover (LCC) change (\%; from Qu et al. 2015b) 
shallow upward moisture transport from BL to FT (via cumulus congestus and shallow overturning circulation over the ocean), cannot be evaluated directly but can be diagnosed indirectly by model outputs (differences of temperature and relative humidity between the $\mathrm{BL}$ and the lower FT; Fig. 2a, and vertical profile of atmospheric circulation; Fig. 2b, see Sherwood et al. 2014 for detail) and can be compared with observations. The LTM consists of two components: small-scale (parameterized process; Fig. 2a) and large-scale LTM (resolved atmospheric circulation; Fig. $2 \mathrm{~b}$ ). In the tropics, water vapor and temperature in the BL air are transported to FT via deep convection (blue arrow in Fig. 2) and LTM. The large-scale LTM (orange arrow in Fig. 2b) is commonly called shallow ascent in the tropics. In the lower FT (Fig. 2a), air parcels transported to the upper troposphere by deep convection turn back with relatively higher temperature and lower relative humidity compared with the environment (red circle in Fig. 2a) due to rain out within the updraft. In contrast, the small-scale LTM (white arrow in Fig. 2a) transports cool and moist air to the lower FT (blue circle in Fig. 2a). In a warming climate, increase in surface evaporation tends to be smaller than the convective $\mathrm{BL}$ dehydration (e.g., Demoto et al. 2013). In addition, models with stronger LTM in the current climate tend to show larger increase in LTM in a warming climate, leading to an LTM control for change in the intensity of convective BL dehydration and resultant cloud feedback. Actually, the sum of the two estimated LTM can explain a half of the ECS spread among 48 CMIP models (Sherwood et al. 2014). The observational constraint suggested a higher ECS range (higher than $3 \mathrm{~K}$ ) than the raw ECS estimate from the multi-model ensemble. While correspondence of LTM and low cloud feedback was not examined sufficiently (Klein and Hall 2015), this conclusion is consistent qualitatively with the above works (Zhai et al. 2015; Qu et al. 2015b; Myers and Norris 2016).

\section{Structural and parametric uncertainty in low cloud feedback}

In the previous section, we reviewed the spread of the low cloud feedback among different climate models. However, the limited size of the CMIP model ensemble does not necessarily cover the whole possible uncertainty range (Tebaldi and Knutti 2007; Collins et al. 2011). Parameterizations of model physics (e.g., convection, cloud microphysics, and turbulence) for reproducing realistic current climatology (Mauritsen et al. 2012) could lead to a biased estimate of the cloud feedback and ECS. Recently, uncertainty due to the behavior of physics schemes implemented in climate models has been addressed by single or multi-model frameworks. PPE is an effective approach to evaluate a sensitivity of cloud feedback and ECS to parameter settings in physics schemes (Murphy et al. 2004; Stainforth et al. 2005; Sanderson et al. 2010; Collins et al. 2011; Klocke et al. 2011). Webb et al. (2015) compared uncertainty ranges of cloud feedback between models which have their convection schemes turned on and off. They concluded that convective parameterization is important in some models, but other processes also contribute to the spread of the cloud feedback among different models.

Yokohata et al. (2010) and Sanderson (2011) compared uncertainty in cloud feedback between PPEs developed a

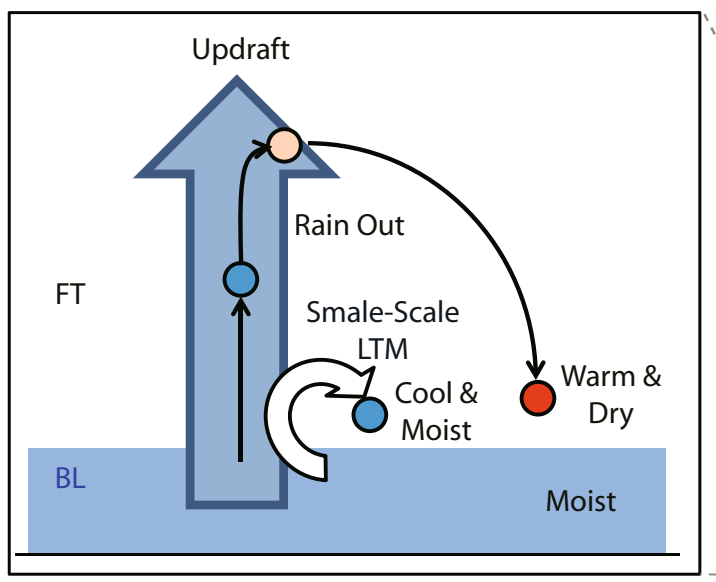

b Large-Scale LTM



Fig. 2 Schematic of lower tropospheric mixing. a Small-scale lower tropospheric mixing (LTM; curved white arrow) between moist BL and dry FT over the tropical ocean (Sherwood et al. 2014). Blue, pink, and red circles represent cool and moist to warm and dry air parcels, respectively. b Largescale LTM (orange arrow) 
by different climate models. They showed that sensitivity of cloud feedback to parameter perturbations was dependent on model structures, suggesting a necessity for evaluating both the parametric and structural (i.e., model configuration) uncertainty. Gettelman et al. (2012) and Watanabe et al. (2012b) developed multi-physics ensembles (MPEs) by swapping model physics schemes between two climate models (old and new versions of the model). They showed that cloud feedback and ECS vary substantially among MPE models (Fig. 3; detailed below), contributing to the difference in cloud feedback and ECS between the two versions of the climate model (Gettelman et al. 2012; Watanabe et al. 2012b). However, MPE also relies on particular parameter settings, implying a possible parametric uncertainty that cannot be addressed by MPE models alone.

To evaluate both the parametric and structural uncertainty, Shiogama et al. (2014) developed a multi-parameter multi-physics ensemble (MPMPE) based on the MPE models developed by two versions of Model for Interdisciplinary Research on Climate (MIROC; Table 2; Watanabe et al. 2012b). They developed PPEs based on the eight MPE models and examined the uncertainty in cloud feedback and ECS. Figure 3 shows the shortwave cloud feedback in the MPMPE (Kamae et al. 2016b) evaluated using the International Satellite Cloud Climatology Project (ISCCP) simulator (Klein and Jakob 1999; Webb et al. 2001) implemented in the models and ISCCP cloud radiative kernel (Zelinka et al. 2012a). Estimated feedbacks were generally consistent with estimates (difference in all-sky and clear-sky TOA radiation) of Shiogama et al. (2014). Compared with MIROC5A with a large negative shortwave cloud feedback and a low ECS, models with swapped physics schemes (cloud, convection, and turbulence) to older ones generally show larger cloud feedback and higher ECS (Table 2; Fig. 3; Watanabe et al. 2012b; Shiogama et al. 2014; Kamae et al. 2016b). The difference in the shortwave cloud feedback among the eight MPE models can largely be attributed to spreads in low cloud and middle cloud feedback over the tropical ocean (Watanabe et al. 2012b). Shiogama et al. (2014) further compared parametric uncertainty between the eight MPE models and concluded that (1) uncertainty in low cloud feedback, middle cloud feedback, and ECS are sensitive to model the structure (consistent with Yokohata et al. 2010 and Sanderson 2011); and (2) the relationship of cloud feedbacks between different cloud levels can influence the total spread of the cloud feedback in a given PPE (e.g., a positive correlation between low and middle cloud feedbacks results in large spreads in total feedback and ECS).

Multiple PPEs with different model structures like MPMPE can cover both the parametric and structural uncertainty. It is needed to examine the physical processes determining total cloud feedback and its components (fractional coverage, clout top height, and optical depth) including low cloud feedback in the multiple PPEs. However, it has not been clarified why different PPEs show different parameter sensitivity of low and middle cloud feedback (Shiogama et al. 2014; Kamae et al. 2016b). Swapping physics schemes like cumulus convection may result in a different behavior of cloud in a control climate and its change in a perturbed climate (Watanabe et al. 2012b). Kamae et al. (2016b) applied the observational constraint of low cloud feedback (LTM) to the MPMPE and concluded that LTM is effective to constrain the uncertainty in low cloud feedback, but is not applicable to total cloud feedback and ECS, at least for a part of PPEs. The physical reasons for the differences in the LTM-ECS relationship among different ensembles are still unclear. Further works are needed to evaluate the uncertainty range of cloud feedback and constrain the ECS uncertainty among multiple PPEs developed by different climate models.

\section{Conclusions}

Historical observations including satellite and implementation of satellite simulator enable to evaluate the reproducibility of the modeled clouds and its variations on seasonal, interannual, and decadal timescales. The accumulated observations suggest that the large-scale controls of LCC can also be applied to the long-term cloud change under global warming. The observationmodel merged approaches suggest that the warmer sea surface and dryer FT relative to BL result in a less LCC, although the larger FT warming relative to $\mathrm{BL}$ enhances the LCC, resulting in a positive low cloud feedback. It is worthwhile to examine whether this physically robust low cloud feedback is also confirmed in multiple PPEs that can cover wider uncertainty ranges than the CMIP multi-models.

In the previous studies, observation-based constraint of the tropical LCC change in a warming climate $(\mathrm{Qu}$ et al. 2015b; Myers and Norris 2016) consists both of the temperature-mediated cloud change and the rapid adjustment (see "Introduction"). Qu et al. (2015a) pointed out the importance of the rapid adjustment on the inversion strengthening in global warming simulations. Bretherton et al. (2013) decomposed the rapid adjustment and temperature-mediated change in low cloud using single LES. Decomposed cloud adjustment and temperature-mediated change should be compared among different models in comprehensive frameworks. In the CFMIP, it has been planned that multiple SCMs are used to conduct sensitivity experiments with SST increase or $\mathrm{CO}_{2}$ increase 

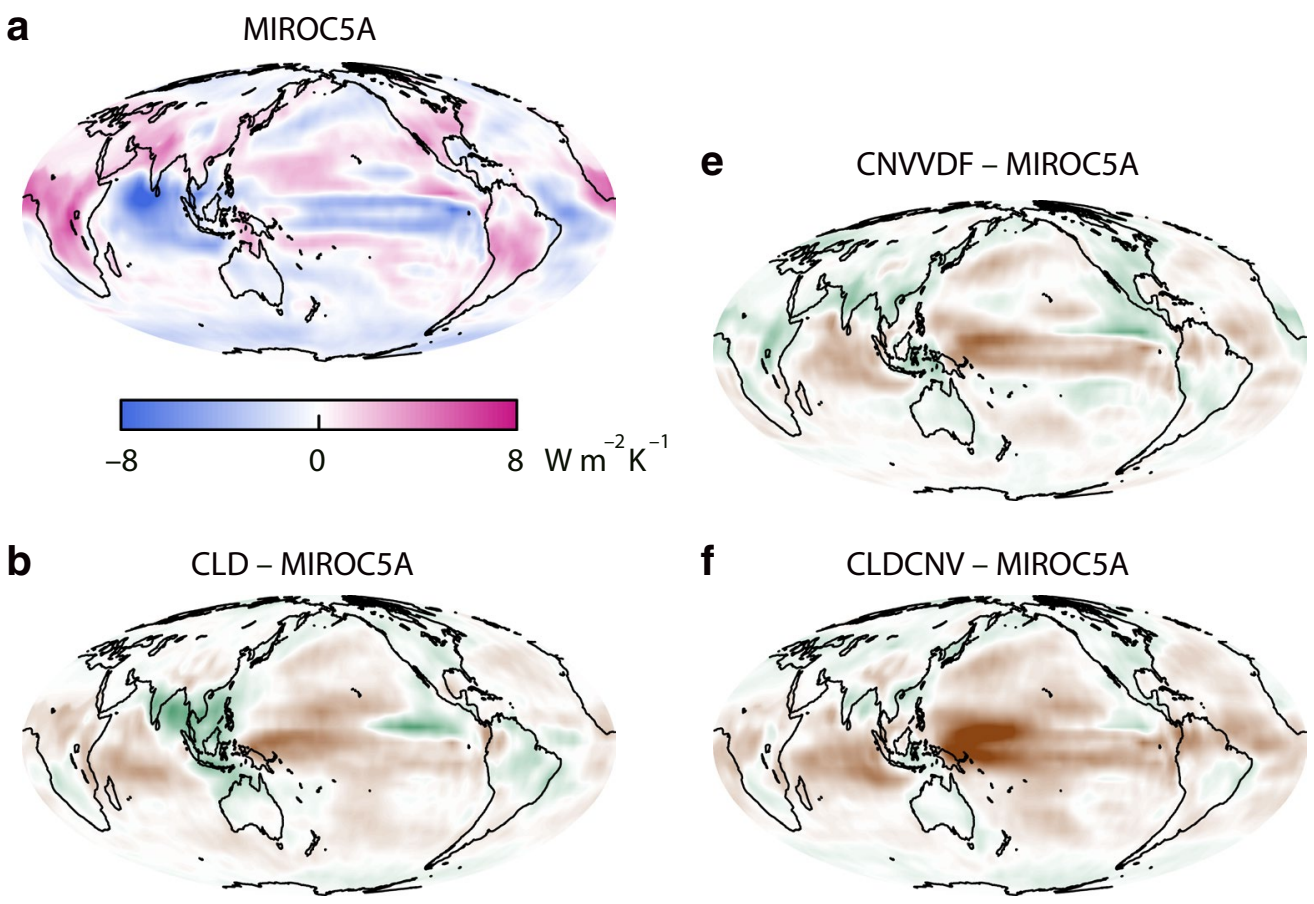

f CLDCNV - MIROC5A
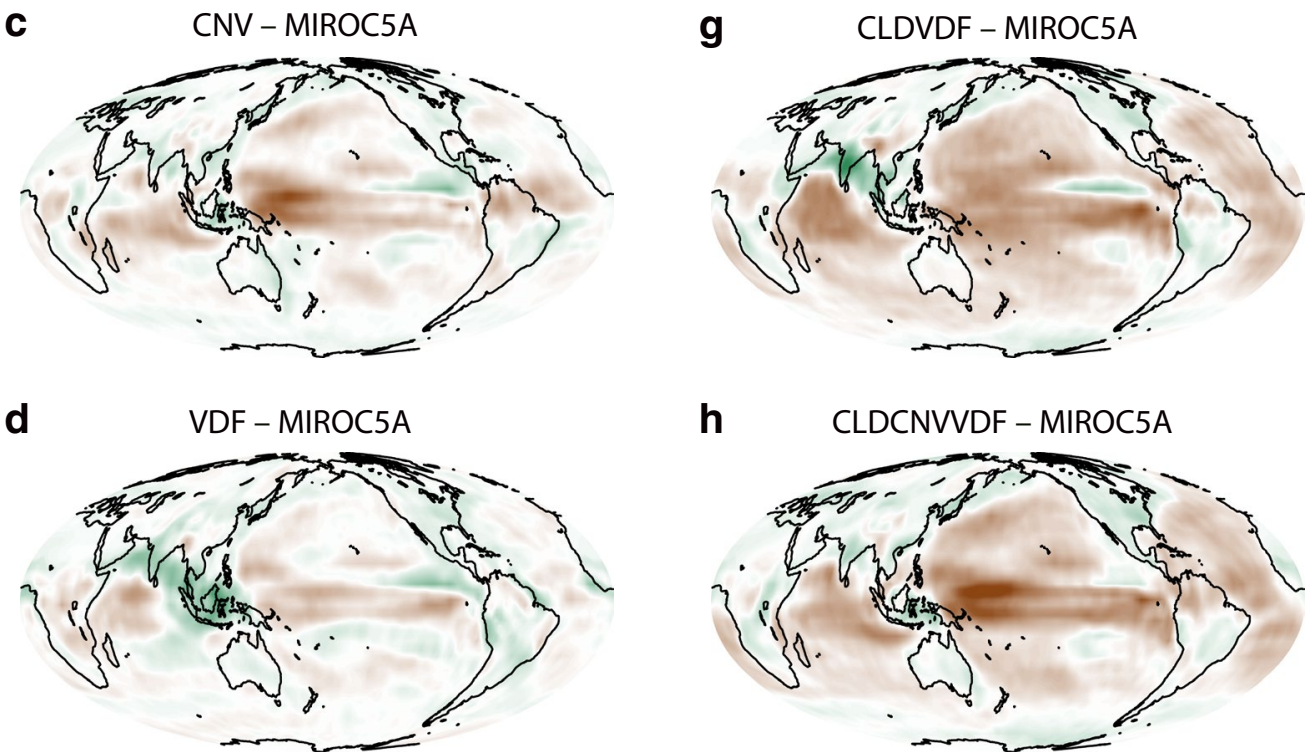

h CLDCNVVDF - MIROC5A
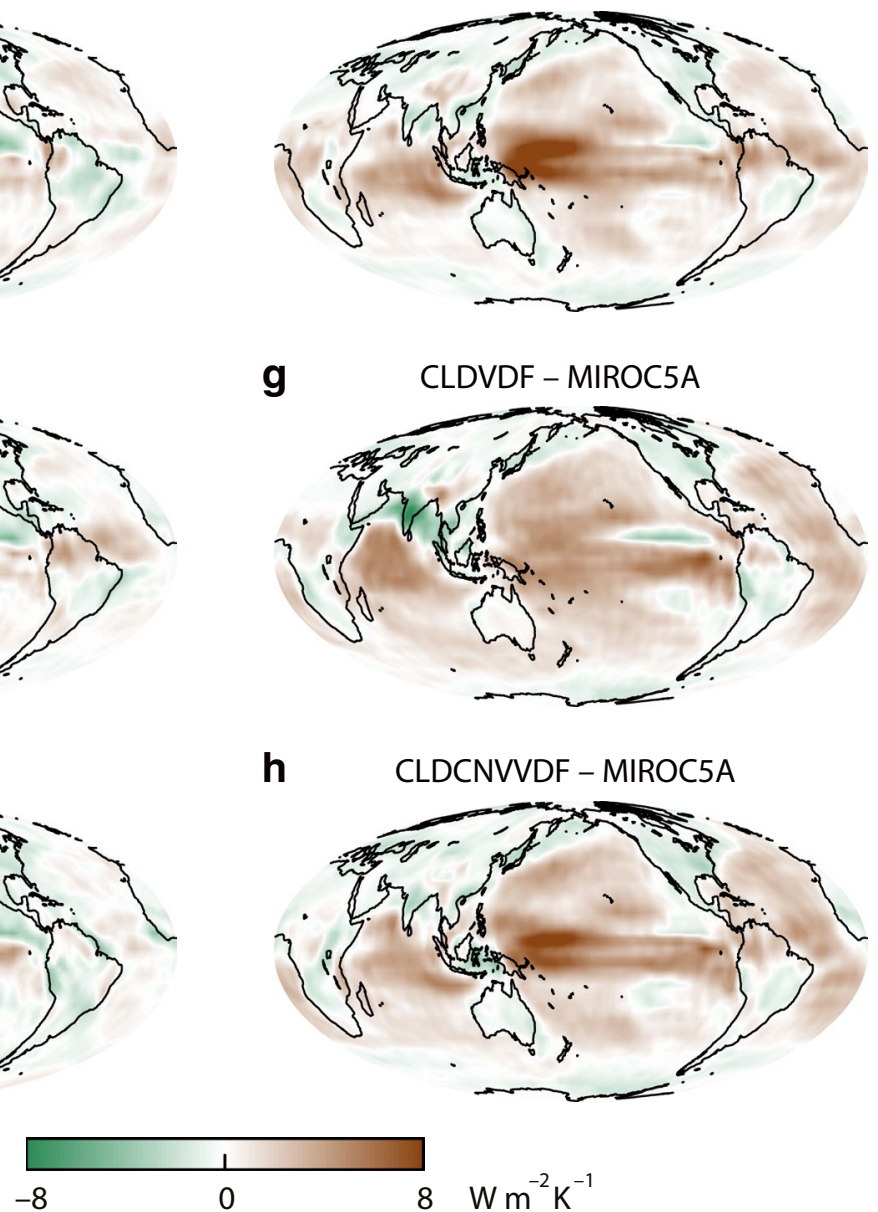

Fig. 3 Variation in shortwave cloud feedback in the MPMPE. a Shortwave cloud feedback $\left(\mathrm{W} \mathrm{m}^{-2} \mathrm{~K}^{-1}\right)$ in MIROC5A model averaged for the PPE members (Table 2; Shiogama et al. 2014; Kamae et al. 2016b). b-h Differences in CLD, CNV, VDF, CNVVDF, CLDVDF, CLDCNV, and CLDCNVVDF models compared with MIROC5A

to evaluate the two effects on the LCC separately. The results of the simulations could contribute to evaluate the robustness of $\mathrm{CO}_{2}$, SST, and other controls of the low cloud feedback among different models.
Evaluating the dependency of uncertainty in cloud feedback on physics schemes is also an ongoing issue. PPEs developed by different models can facilitate the evaluation of the structure dependency of the PPE cloud 
Table 2 Shortwave cloud feedback and ECS in the MPMPE

\begin{tabular}{llllll}
\hline Model & Cloud & $\begin{array}{l}\text { Convec- } \\
\text { tion }\end{array}$ & $\begin{array}{l}\text { Turbu- } \\
\text { lence }\end{array}$ & $\begin{array}{l}\boldsymbol{\lambda}_{\text {swcld }} \\
\left(\mathbf{W ~ m ~ m}^{-2}\right. \\
\mathbf{K}^{-\mathbf{1}} \mathbf{)}\end{array}$ & ECS (K) \\
\hline MIROC5A & & & & -0.24 & 2.35 \\
CLD & MIROC3 & & & -0.08 & 2.81 \\
CNV & & MIROC3 & & -0.07 & 2.48 \\
VDF & & & MIROC3 & -0.36 & 2.69 \\
CNVVDF & & MIROC3 & MIROC3 & -0.17 & 2.83 \\
CLDCNV & MIROC3 & MIROC3 & & 0.39 & 3.16 \\
CLDVDF & MIROC3 & & MIROC3 & 0.50 & 4.86 \\
CLDCNV- & MIROC3 & MIROC3 & MIROC3 & 0.45 & 4.41 \\
VDF & & & & & \\
\hline
\end{tabular}

The left column indicates the eight models constituting the multi-parameter multi-physics ensemble (MPMPE; Shiogama et al. 2014). The second to fourth columns from the left indicate the implemented physics schemes (blank indicates a scheme identical to MIROC5A, and MIROC 3 indicates a scheme identical to MIROC3 climate model; see Table 3 in Shiogama et al. 2014 for details). $\lambda_{\text {sWcld }}$ represents the global mean shortwave cloud feedback $\left(\mathrm{W} \mathrm{m}^{-2} \mathrm{~K}^{-1}\right.$ ) averaged for the PPE members (Kamae et al. 2016b) diagnosed by the satellite cloud simulator (Klein and Jakob 1999; Webb et al. 2001) and cloud radiative kernel (Zelinka et al. 2012a; see text). ECS (K) is derived from Shiogama et al. (2014)

feedback. Different roles of uncertainty in low cloud and middle cloud feedback in multiple PPEs and its physical reasons have not been examined sufficiently. Multi-PPE comparison frameworks may be effective to explore PPE uncertainty in the low cloud feedback and ECS and constrain it by the accumulated observational insights.

\begin{abstract}
Abbreviations
BL: boundary layer; ECS: equilibrium climate sensitivity; CFMIP: Cloud Feedback Model Intercomparison Project; CMIP: Coupled Model Intercomparison Project; FT: free troposphere; ISCCP: International Satellite Cloud Climatology Project; LCC: low cloud cover; LTM: lower tropospheric mixing; MIROC: model for interdisciplinary research on climate; MPE: multi-physics ensemble; MPMPE: multi-parameter multi-physics ensemble; PPE: perturbed physics ensemble; SAT: surface air temperature; SST: sea surface temperature; TCR: transient climate response; TOA: top of the atmosphere.
\end{abstract}

\section{Authors' contributions}

YK wrote the first draft of this paper. TO, HS, and MW commented on the draft. All authors read and approved the final manuscript.

\section{Author details}

${ }^{1}$ Faculty of Life and Environmental Sciences, University of Tsukuba, 1-1-1 Tennoudai, Tsukuba, Ibaraki 305-8506, Japan. ${ }^{2}$ Scripps Institution of Oceanography, University of California San Diego, 9500 Gilman Drive, MC 206, La Jolla, San Diego, CA 92093-0206, USA. ${ }^{3}$ Center for Global Environmental Research, National Institute for Environmental Studies, 16-2, Onogawa, Tsukuba, Ibaraki 305-8506, Japan. ${ }^{4}$ Atmosphere and Ocean Research Institute, The University of Tokyo, 5-1-5 Kashiwanoha, Kashiwa, Chiba 277-8568, Japan.

\section{Acknowledgements}

We thank Kenji Satake and the members of the 2016 AOGS Program Committee for providing us the opportunity to write this review paper. We also thank the two anonymous reviewers for their helpful comments. We acknowledge the scientific guidance of the World Climate Research Programme (WCRP) in promoting this work, coordinated in the framework of WCRP Grand Challenge on Clouds, Circulation and Climate Sensitivity.

\section{Competing interests}

The authors declare that they have no competing interests.

\section{Availability of data and materials}

The code of cloud radiative kernel used in this paper is available from the CFMIP code repository (https://www.code.google.com/archive/p/ cfmip-compute-cloud-feedbacks/).

\section{Funding}

This work was supported by the Program for Risk Information on Climate Change (SOUSEl program) of the Ministry of Education, Culture, Sports, Science and Technology (MEXT), Japan.

Received: 18 April 2016 Accepted: 11 June 2016

Published online: 23 June 2016

\section{References}

Albrecht BA, Jensen MP, Syrett WJ (1995) Marine boundary layer structure and fractional cloudiness. J Geophys Res 100:14209-14222

Andrews T, Ringer MA (2014) Cloud feedbacks, rapid adjustments, and the forcing-response relationship in a transient $\mathrm{CO}_{2}$ reversibility scenario. J Clim 27:1799-1818

Andrews T, Gregory JM, Webb MJ, Taylor KE (2012a) Forcing, feedbacks and climate sensitivity in CMIP5 coupled atmosphere-ocean climate models. Geophys Res Lett 39:L09712. doi:10.1029/2012GL051607

Andrews T, Gregory JM, Forster PM, Webb MJ (2012b) Cloud adjustment and its role in $\mathrm{CO}_{2}$ radiative forcing and climate sensitivity: a review. Surv Geophys 33:619-635

Andrews T, Gregory JM, Webb MJ (2015) The dependence of radiative forcing and feedback on evolving patterns of surface temperature change in climate models. J Clim 28:1630-1648

Blossey PN, Bretherton CS, Zhang M et al (2013) Sensitivity of marine low clouds to an idealized climate change: the CGILS LES intercomparison. J Adv Model Earth Syst 5:234-258

Bodas-Salcedo A, Webb MJ, Bony S et al (2011) COSP: satellite simulation software for model assessment. Bull Am Meteorol Soc 92:1023-1043

Bony S, Dufresne J-L (2005) Marine boundary layer clouds at the heart of tropical cloud feedback uncertainties in climate models. Geophys Res Lett 32:L20806. doi:10.1029/2005GL02385

Bony S, Stevens B, Frierson DMW et al (2015) Clouds, circulation and climate sensitivity. Nat Geosci 8:261-268

Boucher O, Randall D, Artaxo P et al (2014) Clouds and aerosols. In: Stocker TF (ed) Climate change 2013: the physical science basis. Contribution of working group I to the fifth assessment report of the intergovernmental panel on climate change. Cambridge University Press, Cambridge, pp $571-658$

Bretherton CS (2015) Insights into low-latitude cloud feedbacks from highresolution models. Phil Trans R Soc A 373:20140415

Bretherton CS, Blossey PN (2014) Low cloud reduction in a greenhousewarmed climate: results from Lagrangian LES of a subtropical marine cloudiness transition. J Adv Model Earth Syst 6:91-114

Bretherton CS, Blossey PN, Jones CR (2013) Mechanisms of marine low cloud sensitivity to idealized climate perturbations: a single-LES exploration extending the CGILS cases. J Adv Model Earth Syst 5:316-337

Brient F, Bony S (2013) Interpretation of the positive low cloud feedback predicted by a climate model under global warming. Clim Dyn 40:2415-2431

Brient F, Schneider T (2016) Constraints on climate sensitivity from spacebased measurements of low-cloud reflection. J Clim. doi:10.1175/ JCLI-D-15-0897.1

Caldwell PM, Zelinka MD, Taylor KE, Marvel K (2016) Quantifying the sources of inter-model spread in equilibrium climate sensitivity. J Clim 29:513-524

Ceppi P, Hartmann DL (2015) Connections between clouds, radiation, and midlatitude dynamics: a review. Curr Clim Chang Rep 1:94-102

Ceppi P, Hartmann DL, Webb MJ (2016) Mechanisms of the negative shortwave cloud feedback in middle to high latitudes. J Clim 29:139-157

Cess RD, Potter GL, Blanchet JP et al (1990) Intercomparison and interpretation of climate feedback processes in 19 atmospheric general circulation models. J Geophys Res 95:16601-16615 
Charney JG et al (1979) Carbon dioxide and climate: a scientific assessment: report of an ad hoc study group on carbon dioxide and climate, woods hole, Massachusetts, July 23-27, 1979 to the climate research board, assembly of mathematical and physical sciences, National Research Council. National Academy of Sciences. Climate Research Board. http:// books.google.com/books?id=cjOrAAAAYAAJ

Chung D, Teixeira J (2012) A simple model for stratocumulus to shallow cumulus cloud transitions. J Clim 25:2547-2554

Clement AC, Burgman R, Norris JR (2009) Observational and model evidence for positive low-level cloud feedback. Science 325:460-464

Collins M, Booth BBB, Bhaskaran B et al (2011) Climatemodel errors, feedbacks and forcings: a comparison of perturbed physics and multi-model ensembles. Clim Dyn 36:1737-1766

Dal Gesso S, van der Dussen JJ, Siebesma AP et al (2015) A single-column model intercomparison on the stratocumulus representation in presentday and future climate. J Adv Model Earth Syst 7:617-647

Demoto S, Watanabe M, Kamae Y (2013) Mechanism of tropical low-cloud response to surface warming using weather and climate simulations. Geophys Res Lett 40:2427-2432

Dessler AE (2013) Observations of climate feedbacks over 2000-2010 and comparisons to climate models. J Clim 26:333-342

Dufresne J-L, Bony S (2008) An assessment of the primary sources of spread of global warming estimates from coupled atmosphere-ocean models. J Clim 21:5135-5144

Fasullo JT, Sanderson BM, Trenberth KE (2015) Recent progress in constraining climate sensitivity with model ensembles. Curr Clim Chang Rep $1: 268-275$

Flato F, Marotzke J, Abiodun B et al (2014) Evaluation of climate models. In: Stocker TF (ed) Climate change 2013: the physical science basis. Contribution of working group I to the fifth assessment report of the intergovernmental panel on climate change. Cambridge University Press, Cambridge, pp 741-866

Gettelman A, Kay JE, Shell KM (2012) The evolution of climate sensitivity and climate feedbacks in the community atmosphere model. J Clim 25:1453-1469

Gregory JM, Webb MJ (2008) Tropospheric adjustment induces a cloud component in $\mathrm{CO}_{2}$ forcing. J Clim 21:58-71

Hanson HP (1991) Marine stratocumulus climatologies. Int J Climatol 11:147-164

Hartmann DL, Larson K (2002) An important constraint on tropical cloudclimate feedback. Geophys Res Lett 29:1951. doi:10.1029/2002GL015835

Kamae Y, Watanabe M (2013) Tropospheric adjustment to increasing $\mathrm{CO}_{2}$ : its timescale and the role of land-sea contrast. Clim Dyn 41:3007-3024

Kamae Y, Watanabe M, Ogura T, Yoshimori M, Shiogama H (2015) Rapid adjustments of cloud and hydrological cycle to increasing $\mathrm{CO}_{2}$ : a review. Curr Clim Chang Rep 1:103-113

Kamae Y, Ogura T, Watanabe M, Xie S-P, Ueda H (2016a) Robust cloud feedback over tropical land in a warming climate. J Geophys Res Atmos 121:2593-2609

Kamae Y, Shiogama H, Watanabe M, Ogura T, Yokohata T, Kimoto M (2016b) Lower tropospheric mixing as a constraint on cloud feedback in a multiparameter multi-physics ensemble. J Clim. doi:10.1175/JCLI-D-16-0042.1

Klein SA, Hall A (2015) Emergent constraints for cloud feedbacks. Curr Clim Chang Rep 1:276-287

Klein SA, Hartmann DL (1993) The seasonal cycle of low stratiform clouds. J Clim 6:1587-1606

Klein SA, Jakob C (1999) Validation and sensitivities of frontal clouds simulated by the ECMWF model. Mon Weather Rev 127:2514-2531

Klein SA, Hartmann DL, Norris JR (1995) On the relationships among low-cloud structure, sea surface temperature, and atmospheric circulation in the summertime northeast Pacific. J Clim 8:1140-1155

Klocke D, Pincus R, Quaas J (2011) On constraining estimates of climate sensitivity with present-day observations through model weighting. J Clim 24:6092-6099

Knutti R, Hegerl GC (2008) The equilibrium sensitivity of the earth's temperature to radiation changes. Nat Geosci 1:735-743

Lacagnina C, Selten F (2013) A novel diagnostic technique to investigate cloud-controlling factors. J Geophys Res Atmos 118:5979-5991

Long S, Xie S-P, Liu W (2016) Uncertainty in tropical rainfall projections: atmospheric circulation effect and the ocean coupling. J Clim 29:2671-2687

Mansbach DK, Norris JR (2007) Low-level cloud variability over the equatorial cold tongue in observations and models. J Clim 20:1555-1570
Maslin M, Austin P (2012) Uncertainty: climate models at their limit? Nature 486:183-184

Mauritsen T, Stevens B (2015) Missing iris effect as a possible cause of muted hydrological change and high climate sensitivity in models. Nat Geosci 8:346-351

Mauritsen T, Stevens B, Roeckner E et al (2012) Tuning the climate of a global model. J Adv Model Earth Syst 4:M00A01. doi:10.1029/2012MS000154

Medeiros B, Stevens B, Bony S (2014) Using aquaplanets to understand the robust responses of comprehensive climate models to forcing. Clim Dyn 44:1957-1977

Murphy J, Sexton DMH, Barnett DM et al (2004) Quantification of modelling uncertainties in a large ensemble of climate change simulations. Nature 430:768-772

Myers TA, Norris JR (2013) Observational evidence that enhanced subsidence reduces subtropical marine boundary layer cloudiness. J Clim 26:7507-7524

Myers TA, Norris JR (2015) On the relationships between subtropical clouds and meteorology in observations and CMIP3 and CMIP5 models. J Clim 28:2945-2967

Myers TA, Norris JR (2016) Reducing the uncertainty in subtropical cloud feedback. Geophys Res Lett 43:2144-2148

Ogura T, Webb MJ, Watanabe M, Lambert FH, Tsushima Y, Sekiguchi M (2014) Importance of instantaneous radiative forcing for rapid tropospheric adjustment. Clim Dyn 43:1409-1421

Pincus R, Platnick S, Ackerman SA, Hemler RS, Hofmann RJP (2012) Reconciling simulated and observed views of clouds: MODIS, ISCCP, and the limits of instrument simulators. J Clim 25:4699-4720

Qu X, Hall A, Klein SA, Caldwell PM (2014) On the spread of changes in marine low cloud cover in climate model simulations of the 21st century. Clim Dyn 42:2603-2626

Qu X, Hall A, Klein SA, Caldwell PM (2015a) The strength of the tropical inversion and its response to climate change in 18 CMIP5 models. Clim Dyn 45:375-396

Qu X, Hall A, Klein SA, DeAngelis AM (2015b) Positive tropical marine lowcloud cover feedback inferred from cloud-controlling factors. Geophys Res Lett 42:7767-7775

Rieck M, Nuijens L, Stevens B (2012) Marine boundary layer cloud feedbacks in a constant relative humidity atmosphere. J Atmos Sci 69:2538-2550

Ringer MA, Andrews T, Webb MJ (2014) Global-mean radiative feedbacks and forcing in atmosphere-only and coupled atmosphere-ocean climate change experiments. Geophys Res Lett 41:4035-4042

Sanderson BM (2011) A multimodel study of parametric uncertainty in predictions of climate response to rising greenhouse gas concentrations. J Clim 24:1362-1377

Sanderson BM, Shell KM, Ingram W (2010) Climate feedbacks determined using radiative kernels in a multithousand member ensemble of AOGCMs. Clim Dyn 35:1219-1236

Sato M, Tomita H, Yashiro H et al (2014) The non-hydrostatic icosahedral atmospheric model: description and development. Prog Earth Planet Sci 1:18. doi:10.1186/s40645-014-0018-1

Sherwood SC, Ingram W, Tsushima Y, Satoh M, Roberts M, Vidale PL, O'Gorman PA (2010) Relative humidity changes in a warmer climate. J Geophys Res 115:D09104. doi:10.1029/2009JD012585

Sherwood SC, Bony S, Dufresne J-L (2014) Spread in model climate sensitivity traced to atmospheric convective mixing. Nature 505:37-42

Sherwood SC, Bony S, Boucher O, Bretherton C, Forster PM, Gregory JM, Stevens B (2015) Adjustments in the forcing-feedback framework for understanding climate change. Bull Am Meteorol Soc 96:217-228

Shiogama H, Watanabe M, Yoshimori M et al (2012) Perturbed physics ensemble using the MIROC5 coupled atmosphere-ocean GCM without flux corrections: experimental design and results. Clim Dyn 39:3041-3056

Shiogama M, Watanabe M, Ogura T, Yokohata T, Kimoto M (2014) Multi-parameter multi-physics ensemble (MPMPE): a new approach exploring the uncertainties of climate sensitivity. Atmos Sci Lett 15:97-102

Stainforth DA, Aina T, Christensen C et al (2005) Uncertainty in predictions of the climate response to rising levels of greenhouse gases. Nature 433:403-406

Stephens GL (2005) Cloud feedbacks in the climate system: a critical review. J Clim 18:237-273

Stevens B, Bony S (2013) What are climate models missing? Science 340:1053-1054 
Tan I, Storelvmo T, Zelinka MD (2016) Observational constraints on mixedphase clouds imply higher climate sensitivity. Science 352:224-227

Tebaldi C, Knutti R (2007) The use of the multi-model ensemble in probabilistic climate projections. Phil Trans Roy Soc A 365:2053-2075

Tsushima Y, Ringer MA, Webb MJ, Williams KD (2013) Quantitative evaluation of the seasonal variations in climate model cloud regimes. Clim Dyn 41:2679-2696

van der Dussen JJ, de Roode SR, Gesso SD, Siebesma AP (2015) An LES model study of the influence of the free troposphere on the stratocumulus response to a climate perturbation. J Adv Model Earth Syst 7:670-691

Vial J, Dufresne J-L, Bony S (2013) On the interpretation of inter-model spread in CMIP5 climate sensitivity estimates. Clim Dyn 41:3339-3362

Wang X, Liu Y, Bao Q, Wang Z (2012) Climate sensitivity and cloud feedback processes imposed by two different external forcings in an aquaplanet GCM. Theor Appl Climatol 110:1-10

Watanabe M, Shiogama H, Yoshimori M et al (2012a) Fast and slow timescales in the tropical low-cloud response to increasing $\mathrm{CO}_{2}$ in two climate models. Clim Dyn 39:1627-1641

Watanabe M, Shiogama H, Yokohata T et al (2012b) Using a multi-physics ensemble for exploring diversity in cloud-shortwave feedback in GCMs. J Clim 25:5416-5431

Webb MJ, Senior C, Bony S, Morcrette JJ (2001) Combining ERBE and ISCCP data to assess clouds in the Hadley Centre, ECMWF and LMD atmospheric climate models. Clim Dyn 17:905-922

Webb MJ, Senior CA, Sexton DMH et al (2006) On the contribution of local feedback mechanisms to the range of climate sensitivity in two GCM ensembles. Clim Dyn 27:17-38

Webb MJ, Lambert FH, Gregory JM (2013) Origins of differences in climate sensitivity, forcing and feedback in climate models. Clim Dyn 40:677-707

Webb MJ, Lock AP, Bretherton CS et al (2015) The impact of parametrized convection on cloud feedback. Phil Trans R Soc A 373:20140414

Webb MJ, Andrews T, Bodas-Salcedo A et al (2016) The cloud feedback model intercomparison project (CFMIP) contribution to CMIP6. Geosci Model Dev Discuss. doi:10.5194/gmd-2016-70

Wood R, Bretherton CS (2006) On the relationship between stratiform low cloud cover and lower-tropospheric stability. J Clim 19:6425-6432
Wyant MC, Bretherton CS, Blossey PN (2009) Subtropical low cloud response to a warmer climate in a superparameterized climate model. Part l: regime sorting and physical mechanisms. J Adv Model Earth Syst 1:7. doi:10.3894/JAMES.2009.1.7

Ying J, Huang P (2016) Cloud-radiation feedback as a leading source of uncertainty in the tropical Pacific SST warming pattern in CMIP5 models. J Clim 29:3867-3881

Yokohata T, Webb MJ, Collins M, Williams KD, Yoshimori M, Hargreaves JC, Annan JD (2010) Structural similarities and differences in climate responses to $\mathrm{CO}_{2}$ increase between two perturbed physics ensembles. J Clim 23:1392-1410

Yoshimori M, Watanabe M, Shiogama $\mathrm{H}$ et al (2016) A review of progress towards understanding the transient global-mean surface temperature response to radiative perturbation. Prog Earth Planet Sci. doi:10.1186/ s40645-016-0096-3

Zelinka MD, Hartmann DL (2010) Why is longwave cloud feedback positive? J Geophys Res 115:D16117. doi:10.1029/2010JD013817

Zelinka MD, Klein SA, Hartmann DL (2012a) Computing and partitioning cloud feedbacks using cloud property histograms. Part I: cloud radiative kernel. J Clim 25:3715-3735

Zelinka MD, Klein SA, Hartmann DL (2012b) Computing and partitioning cloud feedbacks using cloud property histograms. Part II: attribution to changes in cloud amount, altitude, and optical depth. J Clim 25:3736-3754

Zelinka M, Klein S, Taylor K, Andrews T, Webb M, Gregory J, Forster P (2013) Contributions of different cloud types to feedbacks and rapid adjustments in CMIP5. J Clim 26:5007-5027

Zhai C, Jiang JH, Su H (2015) Long-term cloud change imprinted in seasonal cloud variation: more evidence of high climate sensitivity. Geophys Res Lett 42:8729-8737

Zhang M, Bretherton CS, Blossey PN et al (2013) CGILS: results from the first phase of an international project to understand the physical mechanisms of low cloud feedbacks in single column models. J Adv Model Earth Syst 5:826-842

Zhou C, Zelinka MD, Dessler AE, Klein SA (2015) The relationship between interannual and long-term cloud feedbacks. Geophys Res Lett 42:10463-10469

\section{Submit your manuscript to a SpringerOpen ${ }^{\circ}$ journal and benefit from:}

- Convenient online submission

- Rigorous peer review

- Immediate publication on acceptance

- Open access: articles freely available online

- High visibility within the field

- Retaining the copyright to your article

Submit your next manuscript at $\boldsymbol{\nabla}$ springeropen.com 